\title{
Thrombospondin-1, an Inhibitor of Angiogenesis, Is Regulated by Progesterone in the Human Endometrium
}

\author{
M. Luisa Iruela-Arispe, ${ }^{\star}$ Peggy Porter, ${ }^{\ddagger}$ Paul Bornstein, ${ }^{\S}$ and E. Helene Sage \\ *Departments of Pathology, Beth Israel Hospital and Harvard Medical School, Boston, Massachusetts 02215; and Departments of \\ ${ }^{\ddagger}$ Pathology, "Biological Structure, and ${ }^{\S}$ Biochemistry, University of Washington School of Medicine, Seattle, Washington 98195
}

\begin{abstract}
Thrombospondin-1 (TSP1), a multifunctional extracellular matrix glycoprotein, has been shown to suppress the angiogenic response in vivo and in vitro. We hypothesized that TSP1 might play a role in the inhibition of capillary morphogenesis during the endometrial cycle and examined its expression in 46 human endometrial specimens. Our results show that the expression of TSP1 in the endometrium is $(a)$ cycle-dependent, $(b)$ associated with periods of low capillary growth, and $(c)$ regulated by progesterone. TSP1 protein was identified in the basement membrane of capillaries of the functional endometrium during the secretory phase. Abundant expression of TSP1 mRNA in the secretory phase was also detected by in situ hybridization, in contrast to the low levels seen in the proliferative phase. These findings were confirmed by Northern analysis of proliferative and secretory endometrium. Transcripts for TSP1 were observed predominantly in stromal cells, but signal was also detected in some endothelial and smooth muscle cells. Since the proliferation of endometrial tissue is regulated by steroid hormones, we tested the effects of estrogen and progesterone on TSP1 expression by stromal cells isolated from human endometrium. We found that levels of TSP1 mRNA and protein were increased after incubation with progesterone. Maximal stimulation of mRNA was observed after $8 \mathrm{~h}$ of treatment with 10-50 $\mu \mathrm{M}$ progesterone, and the effect was suppressed by the progesterone antagonist RU-486. Induction by progesterone was cell-specific and equivalent to the stimulation mediated by PDGF. Finally, the levels of TSP1 present in progesterone-stimulated cultures were sufficient to inhibit the migration of endothelial cells in vitro; this effect was nullified by anti-TSP antibodies. We therefore propose that the production of TSP1 at later stages of the endometrial cycle is linked to the inhibition of vessel formation and that TSP1 expression is progesterone-dependent in this tissue. (J. Clin. Invest. 1996. 97:403-412.) Key words: blood vessels • extracellular matrix • endometrial cycle $\bullet$ endothelial cells $\bullet$ steroids
\end{abstract}

Address correspondence to Dr. Luisa Iruela-Arispe, Department of Pathology - RN261, Beth Israel Hospital, 330 Brookline Ave., Boston MA, 02215. FAX: 617-667-3591; Phone: 617-667-3614; E-mail: liruela@bih.harvard.edu

Received for publication 16 March 1995 and accepted in revised form 25 October 1995.

J. Clin. Invest.

(C) The American Society for Clinical Investigation, Inc.

0021-9738/96/01/403/10 \$2.00

Volume 97, Number 2, January 1996, 403-412

\section{Introduction}

Under the stimulatory influence of certain cytokines, endothelial cells convert from a quiescent state to an invasive and proliferative phenotype; this change results in the budding of new capillaries, a process known as angiogenesis. In the normal adult, the expansion of capillary beds is mostly restricted to repair of injury; however, the human endometrium is an exception. Endometrial cycling demands the recurrent growth of new capillaries, since the need for additional vasculature is constantly imposed by the cyclic renewal of the endometrial mucosa. The angiogenic response in the endometrium appears to be tightly controlled, in that accelerated growth is followed by an equally rapid inhibition of growth. Therefore, this tissue provides an interesting model for the study of natural inhibitors of blood vessel morphogenesis in humans.

Thrombospondin-1 (TSP1), ${ }^{1}$ a high molecular weight trimeric glycoprotein originally identified in platelet $\alpha$-granules, was later described as a major secretory product of vascular smooth muscle cells and endothelial cells (1-3). In endothelial cells, TSP1 has been shown to inhibit proliferation (4), disrupt focal adhesions (5), diminish cell spreading (6), and inhibit angiogenesis (7-12). TSP1 suppressed the neovascular response mediated by bFGF in the rat cornea (8), and inhibited capillary formation in vitro (9-10). The region responsible for the antiangiogenic effect has been mapped to the procollagen homology sequence and the type I repeats (11). The specific mechanism that results in angiogenic suppression is not understood and is further complicated by the interaction of TSP1 with a variety of extracellular macromolecules and growth factors. For example, in the presence of type I collagen, TSP1 appears to facilitate rather than inhibit neovessel formation in organ culture (13), and TSP1 binds and activates TGF- $\beta(14,15)$, a recognized angiogenic growth factor $(16,17)$. Therefore, the nature of the extracellular environment and/or the presence of TSP1 as a bound or soluble protein, might determine the ultimate effect of TSP1 on capillary morphogenesis. In fact, the region of TSP1 responsible for the activation of TGF- $\beta 1$ appears to be distinct from the antiangiogenic domain (15). Whether the binding of TGF- $\beta$ provides an additive effect to the angiogenic properties attributed to TSP1 remains to be determined.

An important question is whether endogenous TSP1 blocks blood vessel formation during normal physiological and pathological responses in which angiogenesis is a predominant feature. Since recurrent stimulation and inhibition of capillaries are important characteristics of the cycling human endometrium, we studied the expression and distribution of TSP1

1. Abbreviations used in this paper: $\mathrm{BAE}$, bovine aortic endothelial cells; PCNA, proliferating cell nuclear antigen; RT-PCR, reverse transcriptase-polymerase chain reaction; TSP1, thrombospondin-1. 
in this tissue. Our findings indicate that TSP1 is expressed in the human endometrium during the secretory phase, coincidentally with the suppression of angiogenesis, and that TSP1 is regulated by progesterone in human endometrial stromal cells, but not in human dermal fibroblasts. Moreover, the TSP1 produced by progesterone-stimulated endometrial stromal cells specifically inhibited the directed migration of endothelial cells. These results are consistent with the recognized function of TSP1 as an inhibitor of angiogenesis that might be regulated by progesterone specifically in the secretory phase of the human endometrial cycle.

\section{Methods}

Materials. Paraformaldehyde, Ficoll-400, polyvinylpyrrolidone, salmon testicular DNA, dextran sulfate, RNase A, progesterone, and 17- $\beta$ estradiol were purchased from Sigma Chemical Co. (St. Louis, MO). RU-486 (11 $\beta, 17 \beta)-11-[4-(d i m e t h y l a m i n o) p h e n y l]-17-h y d r o x y-17-(1-$ propynyl estra-4,9-diene-3-one) was the generous gift of Dr. Bruce Kessel (Division of Obstetrics and Gynecology, Beth Israel Hospital, Boston, MA); growth factor-free BSA was a gift from Elaine Raines (Department of Pathology, University of Washington, Seattle, WA). Anti-TSP monoclonal antibodies were obtained from Boehringer Mannheim (Indianapolis, IN). Polyclonal anti-human platelet TSP1 has been described (9). Anti-proliferating cell nuclear antigen (PCNA) antibodies were purchased from Becton Dickinson (San Jose, CA), and anti-progesterone receptor and anti-estrogen receptor antibodies, from Affinity Bioreagents, Inc. (Neshanic Station, NJ). Trypsin-EDTA, collagenase, phenol red-free medium, and antibiotics were from GIBCO BRL (Gaithersburg, MD). Charcoal-filtered fetal calf serum was supplied from Cocalico Biologicals (Reamstown, PA). The random primed DNA-labeling kit and the $\left[{ }^{32} \mathrm{P}\right]-\mathrm{dCTP}(3,000 \mathrm{Ci} /$ mmol) were purchased from Amersham Corp. (Arlington Heights, IL). L-[2,3,4,5- $\left.{ }^{3} \mathrm{H}\right]$-proline and $\left[{ }^{125} \mathrm{I}\right]$-protein A were purchased from NEN (Boston, MA). Nylon membranes (Nytran) were purchased from Schleicher and Schuell (Keene, $\mathrm{NH}$ ). All other reagents used in this study were of the highest purity available from Fisher Biochemicals (Pittsburgh, PA).

Immunocytochemistry and in situ hybridization. Endometrial samples were obtained from hysterectomy specimens from women who underwent surgery for benign indications or conditions that did not compromise the endometrial layer. The age of the patients varied from 29-74 yr. 22 specimens of endometrium were obtained in the proliferative phase, sixteen from the secretory phase, and eight from postmenopausal patients. The phase of the menstrual cycle was determined by histological examination of the tissue. The specimens were obtained from the Pathology Departments of the University of Washington, School of Medicine (Seattle, WA) and from Beth Israel Hospital (Boston, MA). The use of the tissue was approved by the Institutional Human Studies Experimentation Committees at both Institutions.

For immunocytochemistry, the tissues were immersed in methylCarnoy's fixative (60\% methanol, 30\% chloroform, $10 \%$ acetic acid). For in situ hybridization, fixation was done in $4 \%$ paraformaldehyde. Most of the specimens were dehydrated and embedded in paraffin; a few samples were also analyzed as frozen sections. Sections were rehydrated and processed by an avidin-biotin-immunoperoxidase method (Vectastain ABC; Vector Labs, Burlingame, CA), as previously described (19). The primary antibodies included: $(a)$ affinitypurified rabbit anti-TSP-1 (10 $\mu \mathrm{g} / \mathrm{ml})(9)$; $(b)$ mouse anti-human TSP1 antibody, and (c) mouse anti-PCNA.

In situ hybridization was performed as previously described (20). The cDNA fragment used as a template for in situ hybridization was a 1.3-kb EcoRI-EcoRI fragment of human TSP1 cloned into the vector pGEM-2 in an anti-sense orientation relative to SP6. Digestion with EarI provided an antisense riboprobe of 395 bp, when the SP6 polymerase was used, and digestion of the same template with NarI provided a 315-bp sense riboprobe, when T7 RNase polymerase was used. The riboprobes comprised 132 amino acids from the amino terminus of the TSP1 protein. This region is only $33 \%$ identical to TSP 2 at the nucleotide level, and the resulting riboprobes have been shown not to cross-hybridize with other members of the TSP family (20). In addition, when hybridization with a TSP2-specific riboprobe was performed on the same samples, patterns of expression between TSP1 and TSP2 did not overlap (data not shown). The sections were hybridized overnight at $53^{\circ} \mathrm{C}$. Slides were coated with Kodak NTB2 emulsion (Eastman Kodak Co., Rochester, NY) and were exposed in the dark for 2 wk at $48^{\circ} \mathrm{C}$. Hybridization with sense probes served as negative controls.

Both immunocytochemistry and in situ hybridization procedures for experimental and control specimens were done under identical conditions. Two different investigators independently evaluated the degree and pattern of immunostaining.

Isolation of cells and tissue culture. Endometrial samples were minced into $1-2 \mathrm{~mm}^{3}$ pieces under sterile conditions in a laminar flow hood. Fragments were placed into $48-\mathrm{mm}^{2} \mathrm{COSTAR}^{\mathrm{TM}}$ plates. Stromal cells migrated out of the explants after 2-3 d of plating, and explants were removed after $7 \mathrm{~d}$. Cells were grown to confluency in phenol red-free DME containing 10\% charcoal-filtered fetal calf serum, supplemented with $10 \mathrm{nM}$ 17- $\beta$-estradiol, $10 \mu \mathrm{M}$ progesterone, and $100 \mu \mathrm{g} / \mathrm{ml}$ penicillin $\mathrm{G} /$ streptomycin sulfate. At confluence, cultures were incubated in serum-free medium for $2 \mathrm{~d}$ and were treated with steroids, growth factors, or serum. Human dermal fibroblasts were purchased from American Type Culture Collection (Rockville, MD). Dermal fibroblasts, isolated from a 33-yr-old woman (strain DF-33a), were grown under the same conditions used for stromal cells and used in parallel experiments with stromal cells for comparison. To confirm the results obtained with the dermal strain DF-33a, six additional dermal primary cultures isolated from different patients (ages 35-56) were tested. Identical results were obtained.

BAE cells were isolated as previously described (20).

Identification of progesterone receptors in stromal cells. The presence of progesterone receptors in cultured stromal cells was verified by immunocytochemistry and by reverse transcriptase followed by polymerase chain reaction. For immunocytochemistry, stromal cells at passage 3 were plated on glass coverslips, grown until $80 \%$ confluent, and fixed in methyl-Carnoy's solution for $10 \mathrm{~min}$. Cultures were then washed in PBS, blocked in 1\% goat serum, and incubated with $30 \mu \mathrm{g} / \mathrm{ml}$ of anti-progesterone receptor antibody. Detection of immunocomplexes was accomplished with an FITC-conjugated anti-mouse IgG. Negative controls included $(a)$ incubation of stromal cells with secondary antibody alone, and $(b)$ immunocytochemistry on human dermal fibroblasts.

To confirm the expression of progesterone receptors by stromal cells, we subjected RNA to reverse transcriptase followed by PCR analysis. The primers used for the analysis included: 5' CAAAACTTCTTGATAACTTGCA 3' (forward primer) and 5'CACTTTTT ATGAAAGAGAAGGG 3' (reverse primer); oligonucleotides were made by Integrated DNA Technologies (Coralville, IA). We conducted a computer-assisted search (GenBank) of the above progesterone receptor oligo-DNA sequence and found that only progesterone receptor mRNAs of human, mouse, and rat, but not other known sequences, would be expected to hybridize with the above antisense probe. Total RNA from: $(a)$ human cycling endometrium, $(b)$ cultured stromal cells isolated from a 35-year-old human endometrium, (c) cultured stromal cells isolated from a 37-yr-old human endometrium, and $(d)$ cultured dermal fibroblasts, were subjected to reverse transcriptase for the generation of first-strand cDNAs. These cDNAs were subsequently amplified by PCR. The reaction resulted in the predicted $179-\mathrm{bp}$ band. The products were analyzed on a $1.5 \%$ agarose gel.

Metabolic labeling. Cultures were incubated with $50 \mu \mathrm{Ci} / \mathrm{ml}$ of $\mathrm{L}-\left[2,3,4,5-{ }^{3} \mathrm{H}\right]$-proline for $16 \mathrm{~h}$. The conditioned medium was centrifuged to remove cell debris, and proteinase inhibitors were added to 

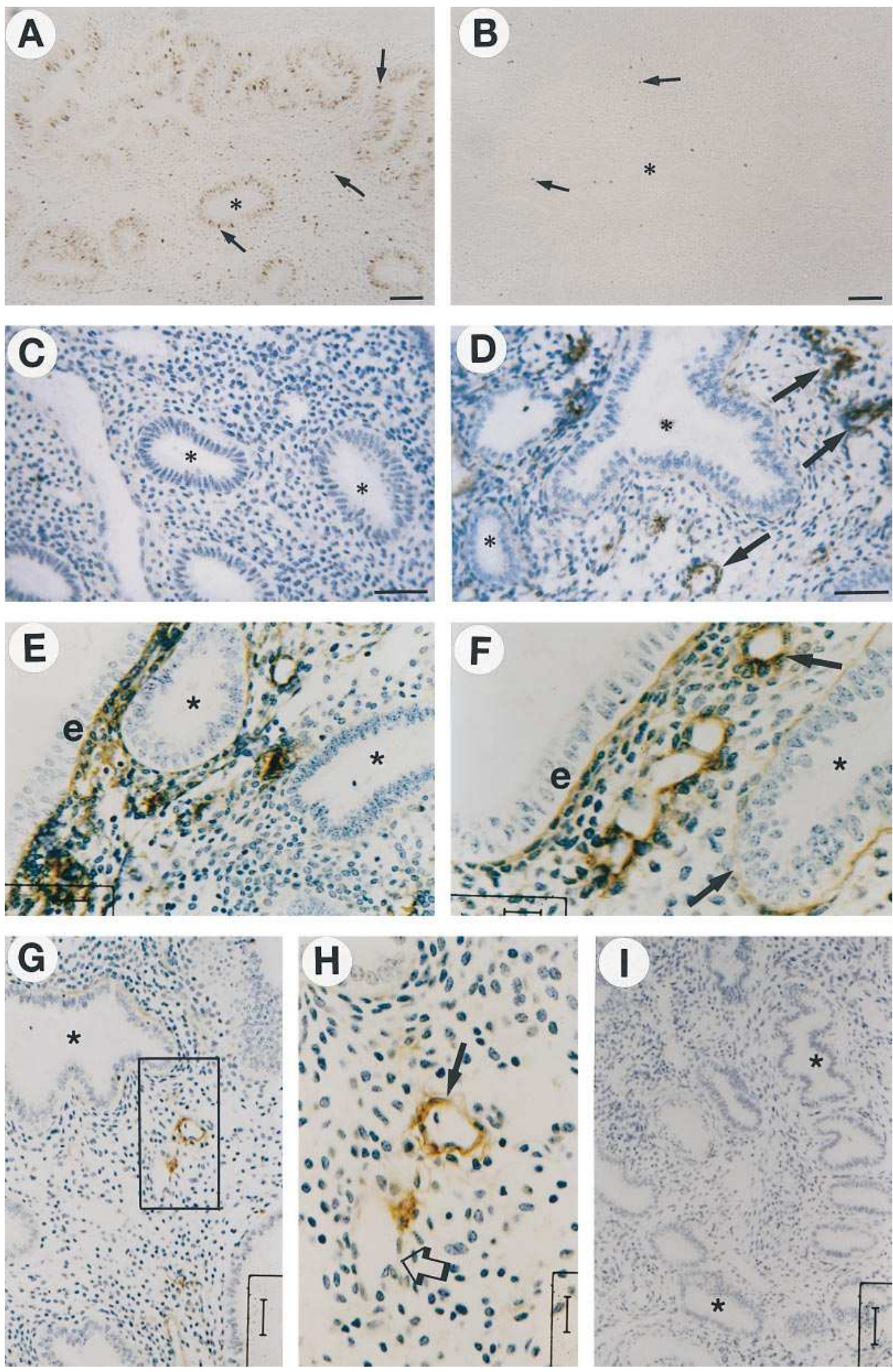

Figure 1. Expression of TSP1 protein in the proliferative and secretory human endometrium. Sections were incubated for $1 \mathrm{~h}$ with antiPCNA IgG ( $A$ and $B)$ or with anti-TSP1 antibody $(C-H)$. Immunocomplexes were identified by an avidin-biotinperoxidase procedure. From the histological profile and relative number of proliferating cells, the proliferative phase $(A$ and $C)$ and secretory phase $(B, D$, and $E-I)$ of the endometrial cycle can be identified. Arrows in $A$ and $B$ indicate nuclei of proliferating cells. No immunoreactivity for TSP1 was detected in proliferative endometrium $(C)$, in contrast to the secretory endometrium $(D)$, in which vessels reactive to antiTSP1 IgG were identified (arrows). In the secretory endometrium, TSP1 was also detected in the subepithelial stroma $(E)$. Higher magnification showed that TSP1 was located extracellularly in the stroma and in the basement membranes of vessels and glands ( $F$, arrows). In the basal endometrium, TSP1 was predominantly in the basement membrane of some blood vessels ( $G$ and $H$ ). Two vessels are shown in $\mathrm{H}$, one containing TSP1 (closed arrow) and one in which TSP1 was not detected (open arrow). A negative control with preimmune serum is shown in I. Asterisks identify glands; $e$, superficial epithelium. Bars: $A-D, 100 \mu \mathrm{m} ; E, 75 \mu \mathrm{m} ; F$ and $H, 25 \mu \mathrm{m} ; G$ and $I$, $125 \mu \mathrm{m}$. produce the following final concentrations: $6.3 \mathrm{mM} \mathrm{N}$-ethylmaleimide; $2 \mathrm{mM}$ phenylmethylsulfonyl fluoride; $25 \mathrm{mM}$ EDTA, and $5 \mu \mathrm{g}$ / $\mathrm{ml}$ pepstatin A. Medium proteins were precipitated in $10 \%$ trichloroacetic acid and were resolved by SDS-PAGE. The cell layers were scraped into PBS containing the same proteinase inhibitors and were sonicated before analysis. In independent experiments, the amounts of samples for SDS-PAGE were normalized according to total pro- tein levels, cell number, or total counts. Since similar results were obtained despite these different criteria, we have presented data from experiments in which the amount of each sample was normalized to cell number (medium from 500,000 cells/lane). Western blots of the same samples were performed as previously described (9); immunocomplexes were detected with ${ }^{125}$ I-protein A and autoradiography. 
Table I. Correlation between Endometrial Phase and Presence of TSP1 in Human Endometrium

\begin{tabular}{|c|c|c|c|c|c|}
\hline Patient & Age & Endometrial phase & Diagnosis & TSP1 & PCNA \\
\hline 1. & 34 & proliferative & n.d. & - & +++ \\
\hline 2. & 36 & proliferative & n.d. & - & + \\
\hline 3. & 36 & proliferative & cervical cancer & - & ++ \\
\hline 4. & 37 & proliferative & ovarian cancer & + & +++ \\
\hline 5. & 39 & proliferative & cervical cancer & + & +++ \\
\hline 6. & 41 & proliferative & leiomyoma & - & +++ \\
\hline 7. & 41 & proliferative & leiomyoma & - & ++ \\
\hline 8. & 42 & proliferative & leiomyoma & + & +++ \\
\hline 9. & 42 & proliferative & n.d. & + & ++ \\
\hline 10. & 42 & proliferative & leiomyoma & - & +++ \\
\hline 11. & 43 & proliferative & leiomyoma & + & +++ \\
\hline 12. & 43 & proliferative & leiomyoma & + & +++ \\
\hline 13. & 44 & proliferative & leiomyoma & - & +++ \\
\hline 14 & 44 & proliferative & cervical cancer & - & +++ \\
\hline 15. & 45 & proliferative & cervical cancer & + & +++ \\
\hline 16. & 45 & proliferative & leiomyoma & - & ++ \\
\hline 17. & 46 & proliferative & ovarian cancer & - & +++ \\
\hline 18. & 47 & proliferative & cervical cancer & - & +++ \\
\hline 19. & 49 & proliferative & n.d. & + & +++ \\
\hline 20. & 48 & weakly proliferative & endometrial cancer & - & + \\
\hline 21. & 37 & mid-secretory & n.d. & ++ & - \\
\hline 22. & 29 & secretory & leiomyoma & + & +++ \\
\hline 23. & 30 & secretory & leiomyoma & ++ & + \\
\hline 24. & 31 & secretory & cervical cancer & +++ & - \\
\hline 25. & 33 & secretory & cervical cancer & + & - \\
\hline 26. & 32 & secretory & leiomyoma & + & - \\
\hline 27. & 37 & secretory & ovarian cancer & +++ & - \\
\hline 28. & 37 & secretory & leiomyoma & ++ & - \\
\hline 29. & 39 & secretory & ovarian cancer & ++ & - \\
\hline 30. & 40 & secretory & leiomyoma & +++ & ++ \\
\hline 31. & 42 & secretory & cervical cancer & +++ & - \\
\hline 32. & 42 & secretory & leiomyoma & +++ & + \\
\hline 33. & 42 & secretory & leiomyoma & + & - \\
\hline 34. & 44 & secretory & n.d. & - & - \\
\hline 35. & 47 & secretory & leiomyoma & +++ & - \\
\hline 36. & 47 & secretory & n.d. & +++ & + \\
\hline 37. & 48 & secretory & leiomyoma & ++ & + \\
\hline 38. & 49 & secretory & ovarian cancer & ++ & + \\
\hline 39. & 44 & inactive & leiomyoma & - & - \\
\hline 40. & 51 & inactive & leiomyoma & - & + \\
\hline 41. & $53 *$ & inactive & leiomyoma & + & + \\
\hline 42. & 55 & inactive & cervical cancer & - & - \\
\hline 43. & 57 & inactive & cervical cancer & - & + \\
\hline 44. & 62 & inactive & leiomyma & - & - \\
\hline 45. & 74 & inactive & n.d. & - & - \\
\hline 46. & 54 & non-phasic & endometritis & - & - \\
\hline
\end{tabular}

Identification of proliferating cells was performed with a PCNA (proliferating cell nuclear antigen) antibody followed by biotinylated secondary IgG and avidin-biotin-peroxidase. The number of proliferating cells and histological characteristics were used to classify the phase of the endometrial cycle. *Estrogen treatment; n.d., not determined; -, none; + , low; ++ , moderate; +++ , high.

Northern analysis. Total RNA was purified from cells by guanidinium-isothiocyanate extraction (22). Samples were subjected to electrophoresis on a denaturing $1.2 \%$ agarose gel. Northern blots were hybridized with ${ }^{32} \mathrm{P}$-labeled cDNA probes. The TSP1 probe cor- responded to a 1.3-kb EcoRI-EcoRI fragment from human TSP1 cDNA (9); the $28 \mathrm{~S}$ rRNA probe was a EcoRI-EcoRI 280-bp fragment from bovine cDNA (23). Membranes were exposed to Kodak XAR-5 film, and densitometric analysis of autoradiograms exposed within the linear response range of the film was performed with a scanning densitometer (Personal Densitometer; Molecular Dynamics Inc., Sunnyvale, MD). Alternatively, we used phosphoImager screens to quantify some of the Northern blots (Molecular Dynamics Inc.). The $28 \mathrm{~S}$ signal was used to correct for loading and transfer inequalities.

The densitometric values were expressed as a percentage of paired samples of nontreated controls (always tested on the same Northern blot), after correction for loading differences with the $28 \mathrm{~S}$ signal, and are shown as mean \pm SEM. Statistical studies were carried out by analysis of variance followed by the Newman-Keuls test for multiple comparisons (24). Differences were considered statistically significant at $P<0.01$.

Migration assays. BAE cells at passages 4-8 were maintained in $10 \%$ FCS until confluence. Cultures were incubated in serum-free DME containing $0.1 \%$ growth factor-free BSA for $48 \mathrm{~h}$, removed from the dishes with trypsin, and replated at a concentration of $10^{4}$ cells/well on the surface of an 8- $\mu \mathrm{m}$ filter (Nucleopore Corporation, Pleasanton, CA) placed in a modified Boyden chamber. The opposite side of the filter was coated with $50 \mu \mathrm{g} / \mathrm{ml}$ of vitrogen (Celtrix) and blocked with $1 \%$ BSA. Cells were allowed to attach and spread. After $2 \mathrm{~h}$ at $37^{\circ} \mathrm{C}$, the following solutions, all containing $10 \mathrm{ng} / \mathrm{ml} \mathrm{bFGF}$, were added to the lower chamber: (a) stromal cell-conditioned media; (b) stromal cell-conditioned media containing $20 \mu \mathrm{M}$ progesterone; $(c)$ stromal cell-conditioned media after exposure to progesterone for $12 \mathrm{~h} ;(d)$ DME containing $10 \mu \mathrm{g}$ TSP1; $(e)$ stromal cell-conditioned media after exposure to progesterone for $12 \mathrm{~h}$ and subsequent incubation with anti-TSP1 antibodies $(20 \mu \mathrm{g} / \mathrm{ml})$ for $6 \mathrm{~h}$; (f) DME containing anti-TSP1 antibodies $(20 \mu \mathrm{g} / \mathrm{ml})$. The conditioned media were obtained from stromal cultures incubated for a total of $24 \mathrm{~h}$ in the absence of FCS. Treatment with progesterone was performed during the second $12 \mathrm{~h}$ of incubation. Addition of bFGF was necessary to stimulate migration; in the absence of bFGF, no significant migration was detected in any of the samples. Results were expressed as percent of migration after subtraction of background (migration in BSA) and are reported as percent of control \pm SE.

Migration was allowed to proceed for $4 \mathrm{~h}$; filters were subsequently fixed for $30 \mathrm{~min}$ in $4 \%$ paraformaldehyde and were stained with $1 \%$ toluidine blue. To obtain statistically significant values, we counted five random fields under the $10 \times$ objective. Experiments were performed in triplicate and were repeated four times. The blocking experiment with anti-TSP antibodies was performed twice. Experiments conducted in the presence of TSP1 were done twice, in triplicate. Two different preparations of TSP1 were evaluated: one was prepared in our laboratory, and the other was provided by Dr. Joanne Murphy-Ullrich (Department of Pathology, University of Alabama, Birmingham). The latter TSP1 had been stripped of contaminating traces of TGF- $\beta 1$.

\section{Results}

Endometrial specimens were obtained from 46 women, 38 of fertile age, and 8 postmenopausal. From the cycling specimens, 22 biopsies were classified as proliferative and 16 as secretory, based on histological criteria. Serial sections from each sample were examined by immunocytochemistry for expression of PCNA and TSP1. In most cases there was an inverse correlation between the presence of TSP1 protein and the proliferation of endometrial cells (Fig. 1, $A-D$ ). Furthermore, within the histological classification of the specimens (proliferative, secretory, or inactive), the expression of TSP1 was restricted to the secretory phase. Tissues from the early proliferative phase 
showed low, or no, immunoreactivity. Table I shows results from all the specimens examined.

We observed TSP1 protein predominantly in the basement membranes of glands, and in small blood vessels and capillaries (Fig. 1, $D-H$, arrows). Identification of vessels with an antiCD34 antibody in serial sections demonstrated that only a subset of capillaries was reactive with anti-TSP-1 antibodies (data not shown). Moreover, immunostaining with PCNA IgG indicated that the presence of TSP1 protein did not, in most instances, correlate with proliferating endothelial cells. TSP1 expression was predominant in the functionalis, which corresponds to the upper two-thirds of the endometrium, and the number of positive microvessels was higher in the subepithelial stroma (Fig. $1 E$ ). Diffuse staining for extracellular TSP1 was also detected in the stroma, particularly in the subepithelial layer (Fig. $1 E$ ). Staining of the stroma was seen only in frozen sections (Fig. 1, E-F). No staining was detected with preimmune serum in either proliferative or secretory endometrium (Fig. 1I).

We also performed in situ hybridization on similar sections to localize TSP1 transcripts. Results were consistent with the immunocytochemical data. Low levels were detected in proliferative endometrium (Fig. $2 \mathrm{~A}$ ), in contrast to the abundant expression of TSP1 mRNA in secretory endometrium (Fig. 2 $B)$. TSP1 mRNA was also observed in endothelial cells, but appeared more abundant in stromal cells of the human endometrium. Whereas high levels of transcript were observed in the functional layer, only background levels, equivalent to the intensity observed during the proliferative phase, were seen in the basal layer (Fig. 2, $C-F$ ). Transcripts were present chiefly in stromal cells from the upper one-third of the endometrium (Fig. $2 F$ ), a result consistent with the location of the protein by immunocytochemistry (Fig. $1 E$ ).

Temporal restriction of TSP1 expression was further confirmed by Northern blot analysis of total RNA samples isolated from proliferative, secretory, and postmenopausal endometrium. TSP1 mRNA was detected in all samples; however, a 3.5-4.2-fold increase in signal was observed in samples from the secretory phase in comparison to samples from the proliferative phase (Fig. 3). These findings, together with our immunohistochemical and in situ hybridization data, indicated that the synthesis of TSP1 might be regulated by steroids.

To study hormonal regulation of TSP1, we isolated endometrial stromal cells and developed conditions for their maintenance in culture. Stromal endometrial fibroblasts exhibited morphological features similar to those of dermal fibroblasts (Fig. $4 \mathrm{~A}$ ). Stromal cells showed high levels of TSP1 by immunocytochemistry (Fig. $4 \mathrm{~B}$ ) and Western blot analysis (not shown). We examined initially the expression of progesterone and estrogen receptors in cultured stromal cells by im-
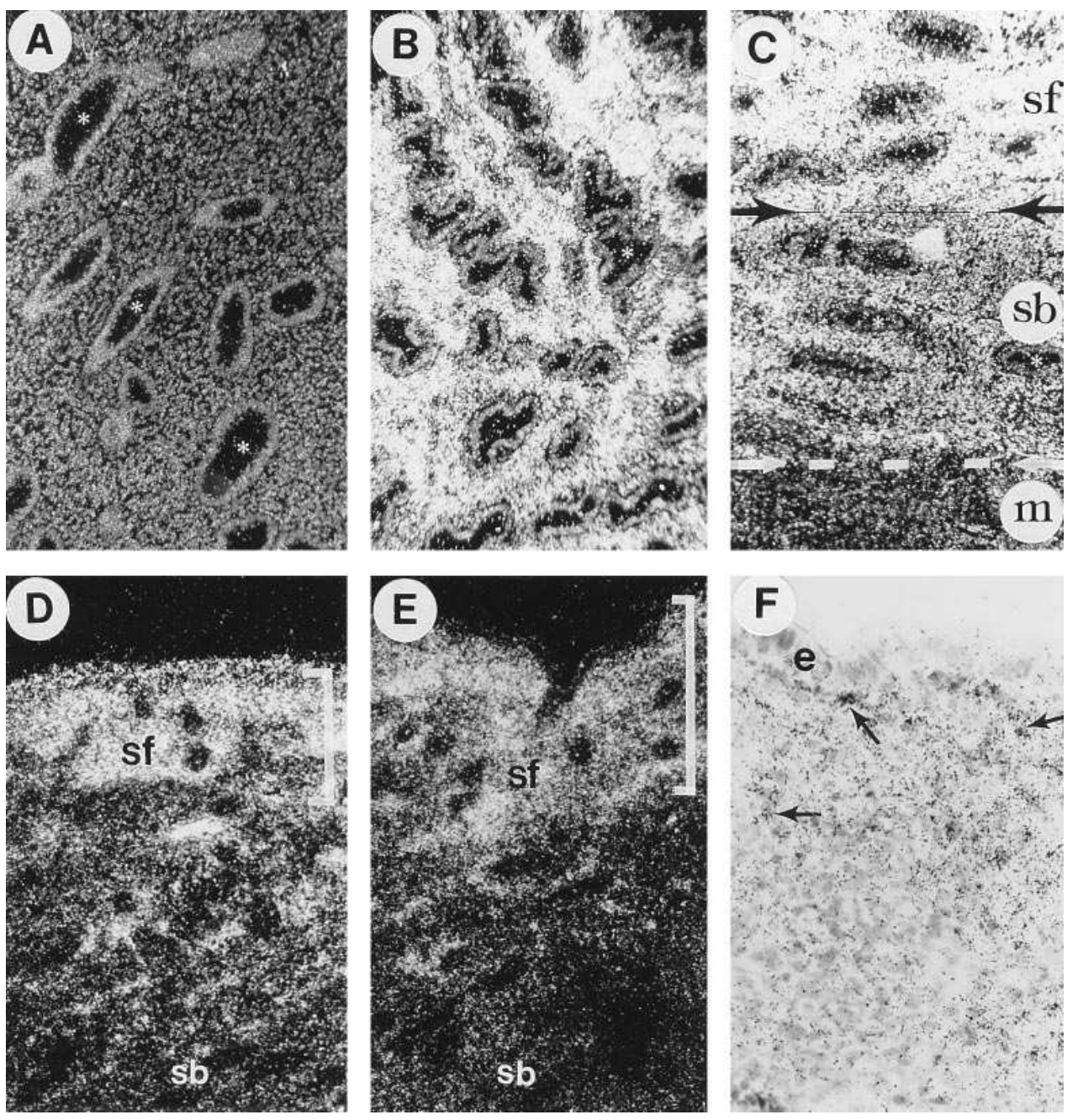

Figure 2. Localization of TSP1 transcripts in the human endometrium by in situ hybridization. All sections were hybridized with anti-sense riboprobes for human TSP1. ( $A$ ) Proliferative phase; $(B-F)$ secretory phase. Note the gradual decrease of TSP1 signal from the stratum functionalis ( $s f$ in $C$ and brackets in $D$ and $E$ ) to the stratum basalis $(s b)$ and the myometrium $(m)$. TSP1 transcripts were predominantly in stromal cells ( $F$, arrows). Asterisks in $A-C$ identify glands, arrows in $C$ indicate the transition of sf to sb and sb to $\mathrm{m} ; e$, epithelium. Bar, $100 \mu \mathrm{m}$. 
Figure 3. Levels of TSP1 mRNA in human endometrial samples. Hybridization of Northern blots was performed with a human TSP1 cDNA probe. After scanning densitometry, the blot was stripped and hybridized with a

28 S rRNA probe. Probes are indicated on the left. Lane 1, Postmenopausal endometrium ( $65 \mathrm{yr}$ old); lane 2, inactive endometrium (40 $\mathrm{yr}$ old); lane 3 , endometrium from proliferative phase ( $25 \mathrm{yr}$ old); lane 4 , endometrium from secretory phase (37 yr old); lane 5 , endometrium from late secretory phase (41 yr old); lane 6, human smooth muscle cells.

munocytochemistry and RT-PCR. Both receptors were present in early-passage cells; however, we observed a gradual decrease in the percentage of positive cells with time in culture that was independent of the presence of estradiol and progesterone in the media. This decrease was not dependent on the endometrial phase (proliferative or secretory) at the time of cell isolation. We examined systematically the levels of progesterone receptor from passages 2-9 and found that, in most primary cultures, steroid receptors were not detected after passage 7 . Therefore, experiments that examined the regulation of TSP1 by steroids were performed on stromal cells of passages 2-4. Expression of the progesterone receptor is shown by immunocytochemistry in Fig. $4 C$. The presence of the progesterone receptor was also confirmed by RT-PCR (Fig. $4 \mathrm{D}$ ). The results indicate that cultured stromal fibroblasts (Fig. $4 \mathrm{D}$, lanes 3 and 4), but not dermal fibroblasts (Fig. $4 D$, lane 5), transcribe mRNA for the progesterone receptor.

In fibroblasts and smooth muscle cells, TSP1 mRNA is increased by serum and PDGF $(25,26)$. TSP1 mRNA was likewise induced in endometrial-derived stromal cells by serum and PDGF (Fig. $5 A$ ); however, in these cells, TSP1 mRNA was also elevated by progesterone (Fig. $5 A$ and $B$ ). Stimulation by progesterone was similar to the effect mediated by PDGF, with increases of 3.1- and 3.6-fold, respectively. The regulation of TSP1 by progesterone was cell-specific, since dermal fibroblasts cultured under identical conditions did not show an increase in steady-state levels of TSP1 mRNA (Fig. 5 $B)$. These experiments were performed on a total of seven independent isolates of human dermal fibroblasts, with identical results. In contrast to the effect mediated by progesterone, TSP1 mRNA levels were not increased by treatment with 17- $\beta$-estradiol (Fig. 5 C). Steady-state levels of TSP1 mRNA in human smooth muscle cells were also not altered during culture in the presence of progesterone or 17- $\beta$-estradiol (Fig. $5 C)$.

The specificity of the response of TSP1 to progesterone was tested with the progesterone analog RU-486, which blocks the function of the progesterone receptor $(27,28)$. After confluent cultures of stromal cells were incubated with RU-486 at concentrations of 1 and $50 \mu \mathrm{M}$, we saw no change in steadystate levels of TSP1 mRNA (Fig. 5 D). Preincubation of cultures with $50 \mu \mathrm{M}$ RU-486, followed by progesterone, suppressed the stimulatory effect mediated by progesterone alone (Fig. $5 \mathrm{D}$ ). This experiment was performed three times with two independent isolates of stromal cells; in each case, identical results were obtained.
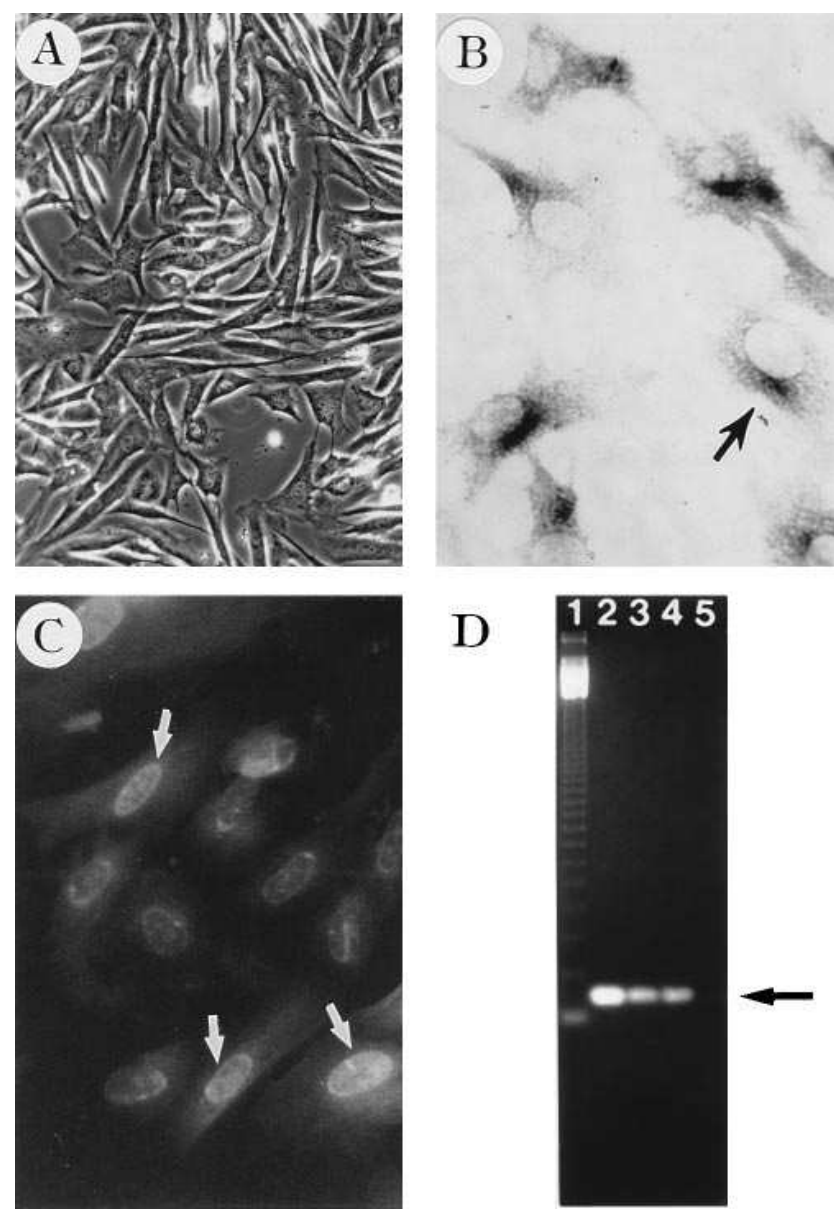

$\mathrm{D}$

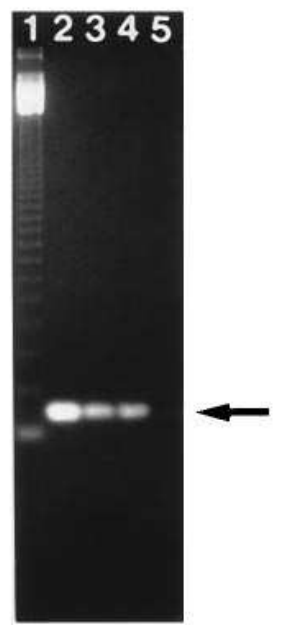

Figure 4. Human endometrial stromal cells in vitro. Isolation and culture of human endometrial stromal cells are described in Methods. $(A)$ Phase-contrast micrograph of stromal cells; $(B)$ immunocytochemical detection of TSP1 (arrow indicates a reactive cell); $(C)$ immunodetection of progesterone receptors in cultured endometrial stromal cells (arrows); (D) identification of 179-bp progesterone receptor fragment produced by RT-PCR. Lanes 1, 123-bp DNA ladder; lane 2, RT-PCR of human endometrium RNA; lane 3, RT-PCR of cultured stromal cells isolated from human endometrium (35-yr-old patient); lane 4, RT-PCR of cultured stromal cells isolated from human endometrium (37-yr-old patient); lane 5, RT-PCR of cultured dermal fibroblasts. Arrow indicates the migration of the predicted 179-bp fragment.

The regulation of TSP1 mRNA by progesterone was concentration-dependent. Stromal cells were grown in steroiddepleted media (Methods), cultured until confluence, and incubated under serum-free conditions for $48 \mathrm{~h}$. This protocol reduces the levels of TSP1 mRNA to what we have termed "baseline." Maximum induction of TSP1 mRNA was seen with 10-20 $\mu \mathrm{M}$ progesterone, although induction of mRNA was detected after incubation with as little as $0.5 \mu \mathrm{M}$ progesterone (Fig. 6). The concentrations of progesterone used in these experiments corresponded to normal physiological levels, which are known to be between 5 and $30 \mu \mathrm{M}$ (29). Further increases in TSP1 were not apparent at concentrations of progesterone above $20 \mu \mathrm{M}$ (Fig. 6). The maximum increase in steady-state levels of TSP1 mRNA was 4.2-fold in human stromal endometrial cells after $6 \mathrm{~h}$ of exposure to progesterone 
A

TSP1

\section{$\begin{array}{llllll}1 & 2 & 3 & 4 & 5 & 6\end{array}$}

$28 S$

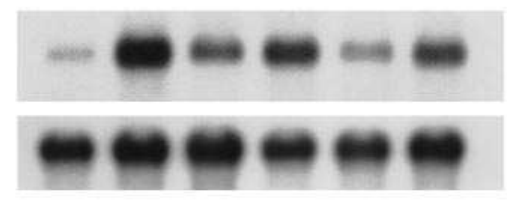

C

TSP1

28S

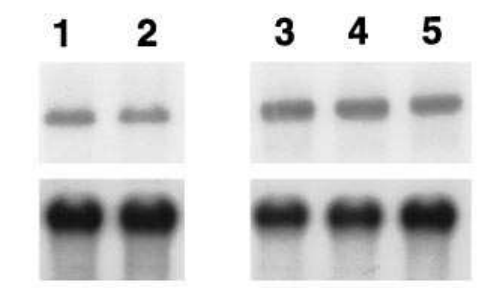

B

TSP1

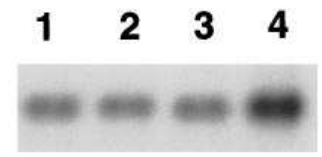

$28 S$

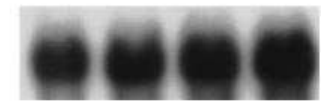

D

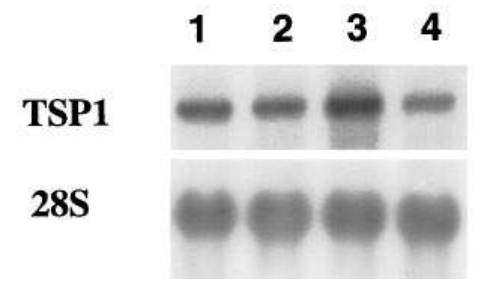

Figure 5. Stimulation of TSP1 mRNA by serum, PDGF-AB, progesterone, and estradiol. (A) Confluent cultures of stromal cells were maintained without serum for $48 \mathrm{~h}$. Cells were subsequently incubated with (lane 1) no serum; (lane 2) $5 \%$ charcoal-filtered FCS; (lane 3) buffer for PDGF-AB; (lane 4) $10 \mathrm{ng} / \mathrm{ml}$ PDGF-AB; (lane 5) buffer for progesterone; (lane 6) $10 \mu \mathrm{M}$ progesterone for $8 \mathrm{~h}$. Total RNA was extracted, subjected to electrophoresis, transferred, and hybridized with probes for TSP1 and $28 \mathrm{~S}$ rRNA. (B) Confluent cultures of dermal fibroblasts and endometrial stromal cells from women of the same age were treated with $10 \mu \mathrm{M}$ progesterone for $8 \mathrm{~h}$. Northern blots were hybridized with probes for TSP1 and

$28 \mathrm{~S}$ rRNA. (Lane 1) dermal fibroblasts and buffer; (lane 2) dermal fibroblasts incubated with $10 \mu \mathrm{M}$ progesterone; (lane 3) stromal cells and buffer; (lane 4) stromal cells incubated with $10 \mu \mathrm{M}$ progesterone. (C) Confluent cultures of stromal cells (lanes 1 and 2) and smooth muscle cells (3-5) were treated with $10 \mathrm{nM} 17-\beta$-estradiol (lanes 2 and 4), $10 \mu \mathrm{M}$ progesterone for $8 \mathrm{~h}$ (lane 5), or DME alone (lanes 1 and 3). Northern blots were hybridized with probes for TSP1 and $28 \mathrm{~S}$ rRNA. (D) Cultures of endometrial stromal cells previously incubated in serum- and steroid-free DME for $48 \mathrm{~h}$ were treated with (lane 1) DME alone; (lane 2) $50 \mu \mathrm{M}$ RU-486; (lane 3) $20 \mu \mathrm{M}$ of progesterone for $4 \mathrm{~h}$, or (lane 4) $50 \mu \mathrm{M}$ RU-486 for $4 \mathrm{~h}$, followed by $20 \mu \mathrm{M}$ of progesterone for $4 \mathrm{~h}$. Resulting RNA blots were hybridized with probes for TSP1 and $28 \mathrm{~S}$ rRNA.

A

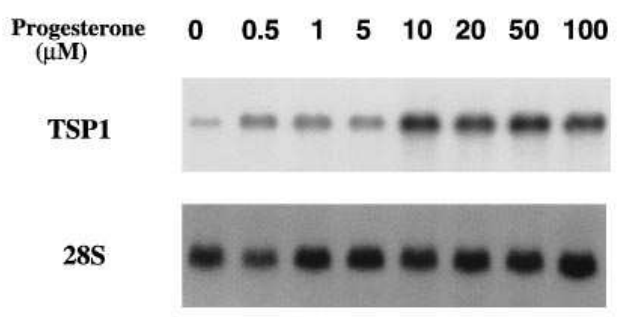

B

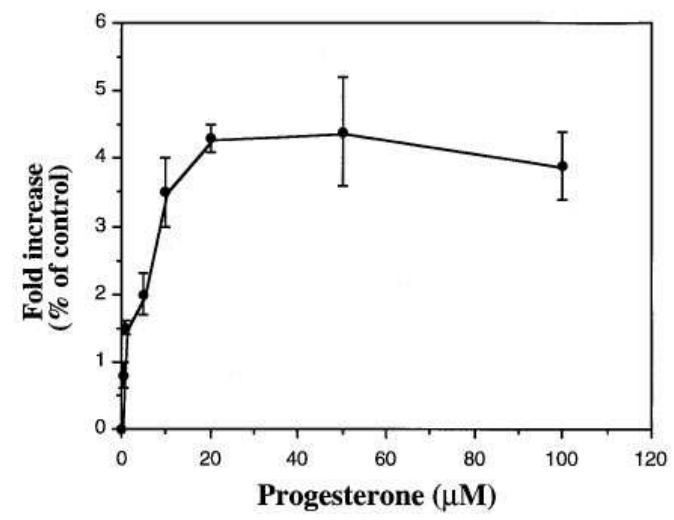

Figure 6. Concentration-dependent response of TSP1 mRNA to progesterone. $(A)$ Cultures of human stromal cells were incubated for $8 \mathrm{~h}$ with increasing concentrations of progesterone. Total RNA was purified and resolved on an agarose gel. Hybridization was performed with a human cDNA TSP1 probe and with a $28 \mathrm{~S}$ rRNA probe for normalization of loading and transfer efficiency. $(B)$ Five independent experiments were scanned by densitometry, normalized to the rRNA signal for $28 \mathrm{~S}$ rRNA, and expressed as fold increase. A concentration of 0 was defined as the baseline (mean $\pm \mathrm{SE})$.
(Fig. 6). These experiments were performed a total of seven times with four strains of stromal cells isolated from both proliferative and secretory endometrium. Northern blots were quantified by densitometry. Signals from various samples were normalized to those corresponding to the $28 \mathrm{~S}$ rRNA and were expressed as percent of control (fold increase; a concentration of 0 was designated baseline). Fig. $6 B$ illustrates the quantification of five independent experiments with three different cell strains.

We also performed time-course experiments with a constant concentration of progesterone. Confluent cultures of stromal cells, subjected to $48 \mathrm{~h}$ of serum-deprivation, were incubated with $10 \mu \mathrm{M}$ progesterone and were harvested at 2, 4, 6,8 , and $24 \mathrm{~h}$. Increased levels of TSP1 mRNA were detected after $4 \mathrm{~h}$; however, maximal induction of 3.8-fold over control occurred after $8 \mathrm{~h}$ (Fig. 7). After $24 \mathrm{~h}$ of incubation with progesterone, levels of TSP1 mRNA were below control values (Fig. 7). This result was reproduced in four independent experiments and was also seen at 36 and $48 \mathrm{~h}$. The data indicate that the regulation of TSP1 by progesterone might be biphasic, with an initial stimulation followed by an inhibition. An alternative explanation is that extended exposure to this hormone decreases the number of progesterone receptors (29) and results in suppression of the stimulatory effect.

Treatment with progesterone resulted in increased levels of secreted TSP1 protein. Cultures of stromal cells were incubated with $10 \mu \mathrm{M}$ progesterone and $\mathrm{L}-\left[2,3,4,5-{ }^{3} \mathrm{H}\right]$-proline for $12 \mathrm{~h}$. Some cultures were also treated with RU-486 for $4 \mathrm{~h}$, before the addition of progesterone and $\mathrm{L}-\left[2,3,4,5-{ }^{3} \mathrm{H}\right]$-proline. Proteins from conditioned media were subjected to electrophoresis, as shown in Fig. $8 \mathrm{~A}$. Although changes in TSP1 were not evident by SDS-PAGE, quantification of Western blots revealed a 2.5-3.5 increase in the levels of TSP1 after exposure 
A

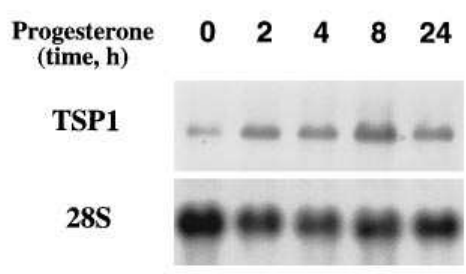

B

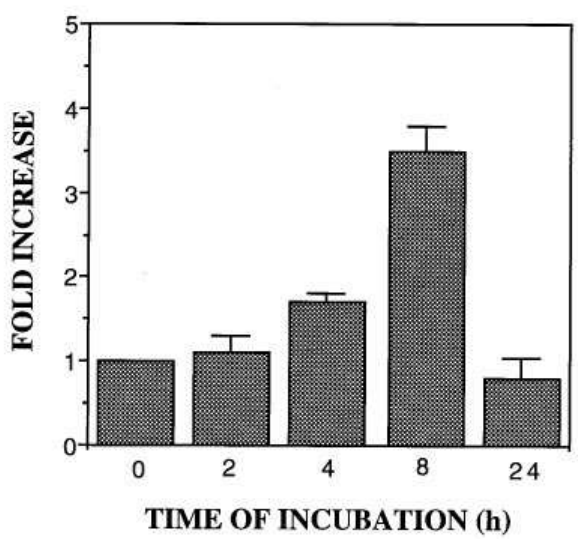

Figure 7. Temporal induction of TSP1 mRNA by progesterone. (A) Human stromal cells were exposed to $10 \mu \mathrm{M}$ progesterone for the times indicated ( 0 to $24 \mathrm{~h}$ ). $7 \mu \mathrm{g}$ of total RNA was resolved on a $1.2 \%$ agarose gel, transferred to Nytran membranes, and hybridized with a TSP1 cDNA probe and a $28 \mathrm{~S}$ rRNA cDNA probe. $(B)$ Blots from four independent experiments were scanned by densitometry, normalized to the corresponding signal for $28 \mathrm{~S}$ rRNA, and expressed as fold increase in the histogram. The absorbance at time 0 was defined as 1 .

of cells to progesterone (Fig. 8 B). RU-486 blocked the effect mediated by progesterone (Fig. $8 B$ ).

To determine whether the increase in TSP1 levels induced by progesterone were sufficient to affect endothelial cell function, we tested the effect of media from stromal cultures on the migration of BAE cells. The experiments were performed in the presence of bFGF, a known stimulator of endothelial cell migration. Conditioned media from stromal cells previously incubated with progesterone for $12 \mathrm{~h}$ inhibited bFGF-mediated migration of BAE cells by $32 \%$ (Fig. 9, column 3 ). Conditioned media from untreated cultures did not show a statistically significant effect on the migration of BAE cells. The inhibition of migration was blocked after neutralizing antibodies against TSP were preincubated with conditioned media from the treated cultures (Fig. 9, column 5). At the concentration used in these experiments, anti-TSP antibodies alone did not alter the migration of endothelial cells. DME containing TSP1 at a concentration comparable to that induced by progesterone produced a similar effect on the inhibition of migration (Fig. 9, column 4). These results indicate that the inhibition of migration of endothelial cells by cultured medium from stromal cells exposed to progesterone could be attributed to TSP1.

\section{Discussion}

The effect of TSP1 on the inhibition of blood vessel formation has been demonstrated both in vivo and in vitro (7-12). Exper-
$\mathbf{A}$

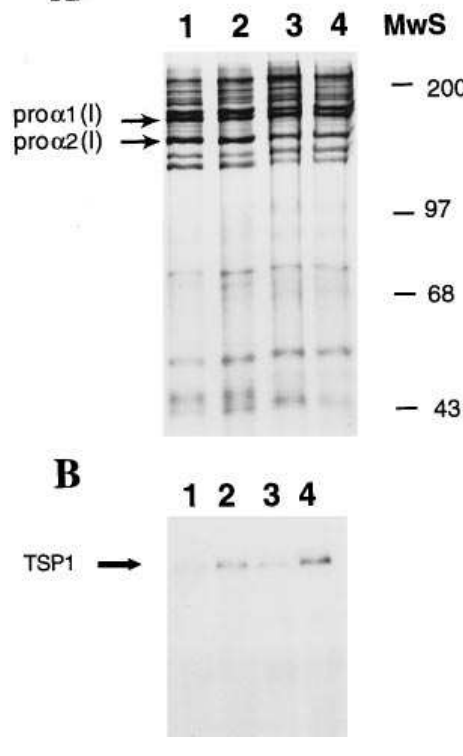

Figure 8. Exposure of human stromal fibroblasts to progesterone increases the level of secreted TSP1 protein. Cultures of stromal fibroblasts were incubated for $4 \mathrm{~h}$ with: (lane 1) DME alone; (lane 2) $10 \mu \mathrm{M}$ progesterone; (lane 3) 50 $\mu \mathrm{M}$ RU-486 for $4 \mathrm{~h}$ followed by $10 \mu \mathrm{M}$ progesterone; (lane 4) $20 \mu \mathrm{M}$ progesterone. After the incubation period, $50 \mu \mathrm{Ci} /$ $\mathrm{ml}\left[2,3,4,5,{ }^{3} \mathrm{H}\right]$-proline was added to each culture. (A) Radiolabeled proteins, secreted by 500,000 cells/ sample, were resolved on a $4 \% / 8 \%$ SDS-PAGE gel under reducing conditions and were visualized by autoradiography. $(B)$ Western blot of the same sam-

ples shown in $(A)$, after incubation with anti-TSP antibodies followed by [ $\left.{ }^{125} \mathrm{I}\right]$ protein A. $M w S$, molecular weight standards.

iments in vivo have focused on the ability of TSP1 to suppress the angiogenic response mediated by bFGF in the corneal pocket assay $(8,11)$; nevertheless, the role of TSP1 as an intrinsic regulator of blood vessel formation at sites of angiogenesis, such as wound repair, tumors, and/or endometrial/ovarian cycling, remains unclear. In this study, we utilized the human endometrium, a site of recurrent angiogenesis, to ask $(a)$ whether TSP1 synthesis occurred in the endometrium, $(b)$ if TSP1 expression was associated with the end of the proliferative phase/beginning of the secretory phase in normal en-

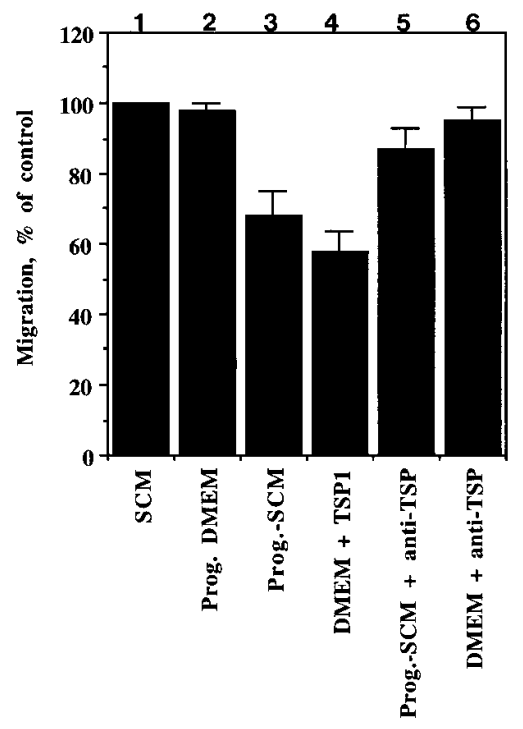

Figure 9. Effect of conditioned media on the migration of endothelial cells. Endothelial cells were plated on a gelatinized filter (pore $=$

$8 \mu \mathrm{m})$. Conditioned media were collected from stromal cultures incubated for $24 \mathrm{~h}$ in the absence of FCS. Migration of endothelial cells was evaluated $4 \mathrm{~h}$ after exposure to the following solutions, all of which contained $10 \mathrm{ng} / \mathrm{ml}$ bFGF: (lane 1) stromal cell-conditioned media (SCM); (lane 2) DME containing $20 \mu \mathrm{M}$ progesterone; (lane 3) stromal cell-conditioned media from cultures exposed to $20 \mu \mathrm{M}$ progesterone for $12 \mathrm{~h}$; (lane 4 ) DME containing $10 \mu \mathrm{g}$ TSP1; (lane 5) media from 2 incubated with anti-TSP1 antibodies ( $20 \mu \mathrm{g} / \mathrm{ml}$ ); (lane 6) DME containing anti-TSP1 $(20 \mu \mathrm{g} / \mathrm{ml})$ alone. Results are expressed as percent of control \pm SE. 0 (or background migration) was equivalent to 5 cells/field; $100 \%$ migration was equivalent to 65 cells/field. 
dometrium, a time when capillary formation is inhibited, and (c) whether TSP1 expression was affected by steroid hormones. We found that TSP1 was expressed at high levels in the functional layer of the endometrium. The peak of expression occurred during the secretory phase and was coincident with the cessation of capillary growth. Finally, we found that TSP1 mRNA and protein were regulated by progesterone and that the increased levels were sufficient to inhibit the migration of endothelial cells.

The human endometrium undergoes cyclic, hormonally dependent changes in proliferation, differentiation, sloughing, and repair. During this process, the need for additional vasculature is constantly imposed by the cyclic differentiation of transient structures and by the recurrent repair of damaged tissues. It has been suggested, but not proven, that the initial wave of capillary proliferation is under the control of steroid hormones (29-31). It is assumed, therefore, that the repair of the endometrial vasculature is mediated by angiogenic and anti-angiogenic factors that are either directly or indirectly inducible by hormones.

An association between angiogenic activity and steroid hormones was initially suggested by experiments in which endometrial tissue was transplanted to the anterior chamber of the monkey eye (32) and to the hamster cheek pouch (33). In both models, the extent of vascularization and incidence of bleeding were influenced by ovarian steroids. These experiments support the concept that the angiogenic response in the primate endometrium is, at some level, dependent on the presence of estrogen and progesterone. Similarly, the regulation of angiogenic inhibitors is likely to be controlled by steroids. Since TSP1 was detected in the human endometrium in a specific phase of the endometrial cycle, we examined the regulation of TSP1 by both estrogen and progesterone. Treatment of stromal cells with physiological levels of $17-\beta$-estradiol did not increase TSP1 expression; however, incubation with progesterone resulted in an approximately fourfold increase in steadystate levels of TSP1 mRNA. This response was dependent on the presence of progesterone receptor, since later-passage cells lacking the receptor did not show an increase in TSP1 mRNA levels. The effects mediated by progesterone occurred at concentrations considered to be available to cells in vivo. Moreover, the increase in TSP1 mRNA by progesterone appeared to be cell specific.

Steroid hormones trigger the binding of specific receptor proteins to promoter/enhancer elements of target genes, an interaction resulting in the activation of transcription (34-35). Analysis of the mouse (36) and human (this report) TSP1 genes revealed the presence of a palindromic consensus sequence that has been reported to interact with the progesterone receptor (35). In the human TSP1 gene we found two progesterone-responsive elements in the promoter. It remains to be seen whether these sites are functional and responsible for the progesterone-inducible response.

Although the possibility that the TSP1 gene might be responsive to steroids had not been explored, previous studies were suggestive of such regulation (37-39). High levels of TSP1 have been reported in other organs sensitive to steroid hormones, such as the mammary gland under both normal and pathological conditions (37). TSP1 protein has also been detected in milk, other breast secretions, and in some types of mammary cystic fluids (40). Interestingly, a study on the kinetics of TSP accumulation in human milk has shown temporal variations which could be due to hormonal regulation. TSP was detected in the initial "aqueous phase" of milk secretion and its levels subsequently fell during the transition to mature milk (38). More recently, changes in plasma TSP1 have also been identified in patients with gynecological malignancies (41).

A number of laboratories have reported inhibition of angiogenesis by steroids (42, 43). For example, glucocorticoids cause regression of hemangiomas if injected directly into the lesion or if given at high doses systemically (44). Since the glucocorticoid and the progesterone receptors share the same nucleotide binding sequence (45), it would be interesting to determine whether the inhibition of blood vessel formation mediated by steroids in these tumors has any correlation with the secretion of TSP1.

The present study did not address the possible role of TSP2 in the inhibition of endometrial angiogenesis. TSP2, a second member of the TSP family, shows a high sequence similarity to TSP1 (3). Both proteins contain the procollagen homology region and type I repeats and have been considered to share anti-angiogenic properties (11). We were unable to detect TSP2 mRNA in the human endometrium (data not shown) or in stromal endometrial cells in vitro. Although the proteins have common structural features and remarkable amino acid similarity, diverse sites of expression (20, this report) and differences in gene regulation $(46,47)$ are indicative of independent functions. Furthermore, the lack of TSP2 in the human endometrium provides compelling evidence that, at least in this organ, the inhibition of capillary formation is dependent on TSP1.

What are the functional consequences of an increase in the levels of TSP1 during the secretory phase of the endometrial cycle? Our data show that the induction of TSP1 by progesterone is sufficient to inhibit the migration of endothelial cells in vitro. We therefore propose that, in the human endometrium, TSP1 antagonizes the effect of angiogenic stimulators that induce endothelial cell migration during angiogenesis.

\section{Acknowledgments}

We thank Drs. Larry Brown and Olivier Kocher for their help in the collection and isolation of human tissue, and Dr. Joanne Murphy-Ullrich (Dept. of Pathology, University of Alabama, Birmingham) for the TGF- $\beta$-free TSP1.

This work was supported by National Institutes of Health grants CA-63356, HL-18645, and DE-08229.

\section{References}

1. Mosher, D. F. 1990. Physiology of thrombospondin. Annu. Rev. Med. 41: 85-97.

2. Frazier, W. A. 1991. Thrombospondins. Curr. Opin. Cell Biol. 3:792-799.

3. Bornstein, P., and E. H. Sage. 1994. The thrombospondins: structure and regulation of expression. Methods Enzymol. 245:63-85.

4. Bagavandoss, P., and J. W. Wilks. 1990. Specific inhibition of endothelial cell proliferation by thrombospondin. Biochem. Biophys. Res. Commun. 170: 867-872.

5. Murphy-Ullrich, J. E., and M. Höök. 1989. Thrombospondin modulates focal adhesions in endothelial cells. J. Cell Biol. 109:1309-1319.

6. Lawler, J., R. Weinstein, and R. O. Hynes. 1988. Cell attachment to thrombospondin: the role of ARG-GLY-ASP, calcium, and integrin receptors. J. Cell Biol. 107:2351-2361.

7. Good, D. J., P. J. Polverini, F. Rastinejad, M. M. Le Beau, R. S. Lemons, W. A. Frazier, and N. P. Bouck. 1990. A tumor suppressor-dependent inhibitor of angiogenesis is immunologically and functionally indistinguishable from a fragment of thrombospondin. Proc. Natl. Acad. Sci. USA. 87:6624-6628.

8. Rastinejad, F., P. J. Polverini, and N. P. Bouck. 1989. Regulation of the activity of a new inhibitor of angiogenesis by a cancer suppressor gene. Cell. 56: 
$345-355$

9. Iruela-Arispe, M. L., P. Bornstein, and H. Sage. 1991. Thrombospondin exerts an antiangiogenic effect on tube formation by endothelial cells in vitro. Proc. Natl. Acad. Sci. USA. 88:5026-5030.

10. DiPietro, L. A., D. R. Nebgen, and P. J. Polverini. 1994. Downregulation of endothelial cell thrombospondin 1 enhances in vitro angiogenesis. $J$. Vasc. Res. 31:178-185.

11. Tolsma, S. S., O. V. Volpert, D. J. Good, W. A. Frazier, P. J. Polverini, and N. Bouck. 1993. Peptides derived from two separate domains of the matrix protein thrombospondin 1 have anti-angiogenic activity. J. Cell Biol. 122:497511.

12. Dameron, K. M., O. V. Volpert, M. A. Tainsky, and N. Bouck. 1994. Control of angiogenesis in fibroblasts by p53 regulation of thrombospondin-1. Science (Wash. DC). 265:1582-1584.

13. Nicosia, R. F., and G. P. Tuszynski. 1994. Matrix-bound thrombospondin promotes angiogenesis in vitro. J. Cell Biol. 124:183-193.

14. Schultz-Cherry, S., S. Ribeiro, L. Gentry, and J. E. Murphy-Ullrich. 1994. Thrombospondin binds and activates the small and large forms of latent transforming growth factor- $\beta$ in a chemically defined system. J. Biol. Chem. 269:26775-26782.

15. Schultz-Cherry, S., J. Lawler, and J. E. Murphy-Ullrich. 1994. The type I repeats of thrombospondin 1 activate latent transforming growth factor- $\beta$. $J$. Biol. Chem. 269:26783-26788.

16. Roberts, A. B., M. B. Sporn, R. K. Assoian, J. M. Smith, N. S. Roche, L. M. Wakefield, U. I. Heine, L. A. Liotta, V. Falanga, J. H. Kehrl, and A. S. Fauci. 1986. Transforming growth factor type-beta: Rapid induction of fibrosis and angiogenesis in vivo and stimulation of collagen formation in vitro. Proc. Natl. Acad. Sci. USA. 83:4167-4171.

17. Iruela-Arispe, M. L., and E. H. Sage. 1993. Endothelial cells exhibiting angiogenesis in vitro proliferate in response to TGF- $\beta 1$. J. Cell. Biochem. 52: 414-430.

18. Raines, E. W., and R. Ross. 1987. Identification and assay of PDGFbinding proteins. Methods Enzymol. 147:48-64.

19. Iruela-Arispe, M. L., P. Hasselaar, and H. Sage. 1991. Differential expression of extracellular proteins is correlated with angiogenesis in vitro. Lab. Invest. 64:174-186.

20. Iruela-Arispe, M. L., D. A. Liska, E. H. Sage, and P. Bornstein. 1993. Differential expression of thrombospondin 1, 2, and 3 during murine development. Dev. Dynam. 197:40-56.

21. Sage, H., E. Crouch, and P. Bornstein. 1979. Collagen synthesis by bovine aortic endothelial cells in culture. Biochemistry. 24:5433-5442.

22. Chomczynski, P., and N. Sacchi. 1987. Single step method of RNA isolation by acid guanidinium thiocyanate-phenol-chloroform extraction. Anal. Biochem. 162:156-159.

23. Iruela-Arispe, M. L., C. A. Diglio, and E. H. Sage. 1991. Modulation of extracellular matrix proteins by endothelial cells undergoing angiogenesis in vitro. Arterioscler. Thromb. 11:805-815.

24. Sokal, R. R., and F. J. Rohlf. 1969. Biometry. The Principles and Practice of Statistics in Biological Research. J. Freeman, San Francisco, CA

25. Framson, P., and P. Bornstein. 1993. A serum response element and a binding site for NF-Y mediate the serum response of the human thrombospondin 1 gene. J. Biol. Chem. 268:4989-4996.

26. Majack, R. A., S. C. Cook, and P. Bornstein. 1985. Platelet-derived growth factor and heparin-like glycosaminoglycans regulate thrombospondin synthesis and deposition in the matrix by smooth muscle cells. J. Cell Biol. 101: 1059-1070.

27. Philibert, D. 1984. RU38486: an original multifaceted antihormone in vivo. In Adrenal Steroid Antagonism. M. K. Agarwal, editor. de Gruyter, New York. 77-101.

28. Beck, C. A., P. A. Estes, B. J. Bona, C. A. Muro-Cacho, S. K. Nordeen, and D. P. Edwards. 1993. The steroid antagonist RU486 exerts different effects on the glucocorticoid and progesterone receptors. Endocrinology. 133:728-739.

29. Clarke, C. L., and R. L. Sutherland. 1990. Progestin regulation of cellular proliferation. Endocr. Rev. 11:266-301.

30. Reynolds, L. P., S. D. Killilea, and D. A. Redmar. 1992. Angiogenesis in the female reproductive system. FASEB J. 6:886-892.

31. Findlay, J. K. 1986. Angiogenesis in reproductive tissues. J. Endocr. 111: 357-366.

32. Markee, J. E. 1940. Menstruation in intraocular endometrial transplants in the rhesus monkey. Contrib. Embryol. 77:221-308.

33. Abel, M. H. 1985. Prostanoids and menstruation. In Mechanisms of menstrual bleeding, Serono Symposium. Vol. 25. D. T. Baird and E. A. Michie, editors. Raven Press, New York. 139-156.

34. Berg, J. M. 1989. DNA binding specificity of steroid hormones. Cell. 57: $1065-1068$.

35. Evans, R. M. 1988. The steroid and thyroid hormone receptor superfamily. Science (Wash. DC). 240:889-893.

36. Lawler, J., M. Duquette, P. Ferro, N. G. Copeland, D. J. Gilbert, and N. A. Jenkins. 1991. Characterization of the murine thrombospondin gene. Genomics. 11:587-600.

37. Pratt, D. A., W. R. Miller, and J. Dawes. 1989. Thrombospondin in malignant and non-malignant breast tissue. Eur. J. Cancer Clin. Oncol. 25:343-350.

38. Dawes, J., P. Clezardin, and D. A. Pratt. 1987. Thrombospondin in milk, other breast secretions, and breast tissue. Sem. Thromb. Hemost. 13:378-384.

39. Dreyfus, M., R. Dardik, B. S. Suh, A. Amsterdam, and J. Lahav. 1992 Differentiation-controlled synthesis and binding of thrombospondin to granulosa cells. Endocrinology. 130:2565-2570.

40. Miller, W. R., and J. Dawes. 1985. Platelet-associated proteins in human breast cyst fluids. Clin. Chim. Acta. 152:37-42.

41. Nathan, F. E., E. Hernandez, C. J. Dunton, J. Treat, H. I. Switalska, R. R. Joseph, and G. P. Tuszynski. 1994. Plasma thrombospondin levels in patients with gynecologic malignancies. Cancer. 73:2853-2858.

42. Crum, R., S. Szabo, and J. Folkman. 1985. A new class of steroids inhibits angiogenesis in the presence of heparin or a heparin fragment. Science (Wash. DC). 230:1375-1378.

43. Ingber, D. E., J. A. Madri, and J. Folkman. 1986. A possible mechanism for inhibition of angiogenesis by angiostatic steroids: induction of capillary basement membrane dissolution. Endocrinology. 119:1768-1775.

44. Weiss, A. H. 1989. Adrenal suppression after corticosteroid injection of periocular hemangiomas. Am. J. Opthalmol. 107:518-522.

45. Beato, M. 1989. Gene regulation by steroid hormones. Cell. 56:335-344.

46. Laherty, C. D., K. O'Rourke, F. W. Wolf, R. Katz, M. F. Seldin, and V. M. Dixit. 1992. Characterization of mouse thrombospondin 2 sequence and expression during cell growth and development. J. Biol. Chem. 267:3274-3281.

47. Bornstein, P., S. Devarayalu, P. Li, C. M. Disteche, and P. Framson 1991. A second thrombospondin gene in the mouse is similar in organization to thrombospondin 1 but does not respond to serum. Proc. Natl. Acad. Sci. USA $88: 8636-8640$ 